\title{
0 conhecimento matemático para o ensino de inequações: um estudo com professores
}

\author{
Mathematical knowledge for the teaching of inequations: a study with \\ teachers
}

\section{Conocimientos matemáticos para la enseñanza de inequidades: un estudio con profesores}

Tanara da Silva Dicetti ${ }^{1}$; Eleni Bisognin ${ }^{2}$; Valdir Pretto ${ }^{3}$

\section{RESUMO}

O presente artigo, refere-se a um recorte de uma pesquisa desenvolvida no Programa de Pós-Graduação em Ensino de Ciências e Matemática, cujo objetivo foi investigar quais conhecimentos para o ensino são identificados nas resoluções de atividades relativas às inequações, apresentadas por um grupo de professores de Matemática. A concepção metodológica desta pesquisa é classificada como uma abordagem qualitativa. 0 levantamento de dados foi realizado por meio de questionários, e o processo de análise de dados foi feito através de categorias definidas pela pesquisadora a partir do conhecimento matemático para o ensino de Ball, Thames, Phelps (2008). Com os resultados obtidos, foi possível verificar as facilidades e fragilidades dos professores no que se refere ao ensino de inequações, bem como a manifestação do conhecimento matemático para ele. Entendemos, ainda, que o trabalho desenvolvido favorece a observação da fragilidade dos professores em alguns conhecimentos para o ensino de inequação, abrindo espaço para novas pesquisas que envolvam/proponham formações - iniciais e/ou continuadas - no que se refere a diferentes abordagens algébricas.

Palavras-chave: Ensino de Matemática; Álgebra; Inequação; Conhecimento Pedagógico do Conteúdo.

\begin{abstract}
This article refers to an excerpt of a research developed in the Graduate Program in Science and Mathematics Teaching, whose objective was to investigate which knowledge for teaching is identified in the resolutions of activities related to inequalities, presented by a group of Mathematics teachers. The methodological design of this research is classified as a qualitative approach. The data collection was carried out through questionnaires, and the data analysis process was carried out through categories defined by the researcher based on mathematical knowledge for teaching Ball, Thames, Phelps (2008). With the results obtained, it was possible to verify the facilities and weaknesses of teachers with regard to teaching inequalities, as well as the manifestation of mathematical knowledge for them. We also understand that the work developed favors the observation of the fragility of teachers in some knowledge for teaching inequality, opening space for new research involving/proposing training - initial and/or continued - with regard to different algebraic approaches.
\end{abstract}

Keywords: Teaching of Mathematics; Algebra; Inequality; Content Pedagogical Knowledge.

\footnotetext{
${ }^{1}$ Licenciada em Matemática, Mestranda no Programa de Pós-graduação em Ensino de Ciências e Matemática da Universidade Franciscana (UFN) e Professora do Colégio Divino Coração, Alegrete/RS - Brasil. E-mail: tanarasdicetti@gmail.com

2 Doutora em Matemática e Professora do Programa de Pós-graduação em Ensino de Ciências e Matemática da Universidade Franciscana (UFN), Santa Maria/RS - Brasil. E-mail: eleni.bisognin@gmail.com

${ }^{3}$ Doutor em Ciências da Educação e Professor do Programa de Pós-graduação em Ensino de Ciências e Matemática da Universidade Franciscana (UFN), Santa Maria/RS - Brasil. E-mail: prettov@gmail.com
} 


\section{RESUMEN}

Este artículo hace referencia a un extracto de una investigación desarrollada en el Programa de Posgrado en Docencia de las Ciencias y las Matemáticas, cuyo objetivo fue indagar qué conocimientos para la docencia se identifican en las resoluciones de actividades relacionadas con las desigualdades, presentado por un grupo de profesores de Matemáticas. El diseño metodológico de esta investigación se clasifica como enfoque cualitativo. La recolección de datos se realizó a través de cuestionarios y el proceso de análisis de datos se realizó a través de categorías definidas por el investigador con base en los conocimientos matemáticos para la enseñanza de Ball, Thames, Phelps (2008). Con los resultados obtenidos, fue posible verificar las facilidades y debilidades de los docentes con respecto a las desigualdades docentes, así como la manifestación de conocimientos matemáticos para ellos. También entendemos que el trabajo realizado favorece la constatación de la debilidad de dos docentes en algún conocimiento para la desigualdad docente o docente, abriendo espacio para nuevas investigaciones que involucren/propongan formación -iniciada y/o continuada-, no que se refiera a enfoques algebraicos diferentes.

Palabras clave: Enseñanza de las matemáticas; Álgebra; Inecuación; Conocimiento pedagógico del contenido.

\section{INTRODUÇÃO}

Analisando pesquisas do Instituto de Estudos e Pesquisas Educacionais Anísio Teixeira (INEP) como, por exemplo, a do Sistema de Avaliação da Educação Básica (SAEB) que consiste em um teste aplicado, a cada dois anos, na rede pública de ensino e em uma amostra da rede privada, a qual tem o intuito de refletir os níveis de aprendizagem dos estudantes, constatou-se que há uma defasagem na aprendizagem de Matemática, pois, segundo dados do SAEB do ano de 2019, 21,66\% dos estudantes do Ensino Fundamental da rede estadual do Rio Grande do Sul estão no nível 4 de proficiência.

Ferreira (2017) destaca duas hipóteses para justificar a defasagem dos estudantes no que se refere à Álgebra, sendo elas: o grande nível de abstração dos conteúdos algébricos, próprio do pensamento algébrico, e a forma pela qual é abordada no processo de ensino e aprendizagem. Neste sentido, Freire (2011) destaca que o baixo desempenho dos estudantes na Álgebra não é restrito às dificuldades próprias da área, mas também do processo de ensino e aprendizagem, o qual é centrado em regras e procedimentos mecânicos.

Corroborando Fiorentini, Miorim e Miguel (1993) destacam que o ensino da álgebra é reduzido ao transformismo algébrico, dando mais ênfase na linguagem algébrica do que no pensamento algébrico e em seu significado. Logo o ensino da álgebra deve ser repensado, pois, segundo os autores supracitado, há uma subordinação entre a linguagem e o pensamento algébrico, pois há elementos comuns tanto ao pensamento algébrico quanto a Álgebra.

Deve ser considerado, no entanto, que se existem essas dificuldades por parte dos estudantes, pode ser que a problemática esteja na confluência do processo de ensino e aprendizagem, e o conhecimento matemático para o ensino do professor. Nesse sentido, os Parâmetros Curriculares Nacionais (PCN) destacam que

[...] há problemas a serem enfrentados, tais como a necessidade de reverter um ensino centrado em procedimentos mecânicos, desprovidos de significados para o aluno. Há urgência em reformular objetivos, rever conteúdos e buscar metodologias compatíveis com a formação que hoje a sociedade reclama. (BRASIL, 1998, p. 15) 
Para que haja uma mudança no cenário atual da Educação Matemática, é preciso que haja uma mudança no ensino da Matemática. Acredita-se que o processo de ensino e aprendizagem não é mão única, principalmente no que se refere à disciplina de Matemática. Por isso, a importância dos professores terem conhecimentos de diferentes teorias e metodologias de modo a melhorarem a sua prática na sala de aula.

Pesquisas como as de Lee Shulman $(1986,1987)$ e Deborah Loewenberg Ball, Mark Hoover Thames, Geoffrey Phelps (2008) elencam conhecimentos necessários ao professor para que suas práticas consigam, de fato, contribuir no processo de ensino e aprendizagem de seus estudantes de forma significativa e não meramente mecânica. De acordo com Shulman (1987), os professores apresentam dificuldades de articular o que sabem e como sabem, o que é fundamental para o ensino, pois esse começa quando o professor tem a compreensão do que deve ser aprendido e como deve ser ensinado. Assim Shulman $(1986,1987)$ destaca uma base de conhecimento para o ensino, a qual descreve conhecimentos e habilidades necessários para se efetivar como professor.

Nesse sentido Ball, Thames e Phelps (2008) demonstram como se dá o processo de transição do "status" aprendiz para o de professor. Tendo como base a teoria de Shulman, Ball, Thames e Phelps (2008) elaboram o que denominam de "conhecimento matemático para o ensino", a partir dos seguintes questionamentos: "O que os professores precisam saber e serem capazes de fazer para ensinar efetivamente? Ou o que o ensino eficaz exige em termos de compreensão de conteúdo?" (BALL, THAMES E PHELPS, 2008, p. 394). Ao investigar a natureza, o papel e a importância dos diversos tipos de conhecimentos para o ensino de Matemática, eles observaram que o conhecimento obtido da prática é bastante amplo.

A motivação dessa pesquisa deu-se por observar as dificuldades que os estudantes têm em relação à Álgebra. Considerando que a área da Álgebra é vasta, optamos por delimitar este estudo, olhando para um conceito específico. Ao elencarmos alguns tópicos, decidimos por pesquisar sobre inequações pois há carência de estudos sobre este tópico nos Anos Iniciais do Ensino Fundamental II, fato que não favorece o desenvolvimento do pensamento algébrico.

Ao fazer uma busca em periódicos da área, encontramos poucos trabalhos referentes ao estudo de inequações, nos últimos 5 anos, mesmo as inequações sendo um conteúdo importante, pois são a base de estudo para vários outros conteúdos de Matemática como trigonometria, função, programação linear, tratamento da informação, entre outros, além da sua utilização na Física e Química. São usadas também em outras áreas do conhecimento, como Ciência da computação e Engenharia.

Diante disso, com o objetivo de investigar quais conhecimentos para o ensino são identificados nas resoluções de atividades relativas às inequações, apresentadas por um grupo de professores de Matemática, foi desenvolvida uma pesquisa de mestrado no Programa de Pós-Graduação em Ensino de Ciências e Matemática do Rio Grande do Sul. O presente artigo é um recorte desta pesquisa e apresenta alguns de seus resultados.

\section{REFERENCIAL TEÓRICO}

As discussões acerca dos conhecimentos necessários para o ensino são motivos de pesquisas nas últimas décadas. Indaga-se que a formação de um professor não finaliza no momento em que ele termina uma graduação em uma área de conhecimento específica, e sim, é o ponto inicial da 
construção do conhecimento. A identidade do professor vai se constituindo na prática docente, mas, para começar a sua atuação, deve-se ter uma base de conhecimento sólida, base essa que é motivo de pesquisas constantes.

Lee Shulman $(1986,1987)$ é um dos pesquisadores-referência sobre os conhecimentos e habilidades necessários a um professor competente; a este estudo ele chamou de base de conhecimento para o ensino (knowledge base for teaching). Baseados na noção de conhecimento pedagógico do conteúdo, Debora Ball e colaboradores aprofundam suas pesquisas, direcionando-as para a área de Matemática, chamando então de conhecimento matemático para o ensino (mathematical knowledge for teaching).

Por muito tempo, segundo Shulman (1986), houve uma separação/distinção entre o conteúdo e o processo pedagógico, logo, suas pesquisas sugerem um conjunto de conhecimentos, o qual todo professor deve dominar para então desempenhar a sua prática docente da melhor maneira a facilitar o aprendizado dos estudantes. Para Shulman (1986, p. 8), "É provável que o mero conhecimento de conteúdo seja tão inútil pedagogicamente quanto a habilidade sem conteúdo." ${ }^{4}$ Nesse viés, é importante prestar atenção nesses dois aspectos, para assim se desenvolver como professor. Shulman (1986) destaca três categorias necessárias ao conhecimento do professor, sendo elas: (a) conhecimento do conteúdo da matéria, (b) conhecimento pedagógico do conteúdo e (c) conhecimento curricular.

Com um olhar para os estudos de Shulman, Ball, Thames, Phelps (2008), buscaram se aprofundar e trazer novas discussões, voltando-se para a Matemática. Eles acreditam que o termo "Conhecimento Pedagógico do Conteúdo" é de extrema importância para o ensino, mas que não está bem definido, sendo muito amplo este conceito determinado por Shulman, além de haver diferentes maneiras no uso deste termo, ao relacionar o conhecimento do conteúdo com a prática de ensino. Nesse sentido, "[...] após duas décadas de trabalho, essa ponte entre conhecimento e prática foi ainda pouco compreendida, e o arcabouço teórico coerente, que Shulman (1986, p. 9) pedia, permaneceu subdesenvolvido." (BALL, THAMES, PHELPS, 2008, p. 389).

Sendo assim, o termo necessita de uma definição indubitável com fundamentações empíricas (BALL, THAMES, PHELPS, 2008). Baseando-se nas ideias iniciais de Shulman, os autores usaram uma abordagem empírica para, então, aprofundar o entendimento sobre o conteúdo necessário para o ensino. Sua abordagem permite investigar a natureza, o papel e a importância dos diversos tipos de conhecimentos para o ensino de Matemática, observando, assim, que o conhecimento que pode ser obtido da prática é amplo. Para Shulman (1987, p. 9), "Uma base de conhecimento para o ensino não é fixa e final."

Em seu trabalho, Ball, Thames, Phelps (2008) concentram-se em refinar o conceito de conhecimento pedagógico de conteúdo e estabelecem, então, as bases para a teoria a qual eles denominaram de "Conhecimento Matemático para o Ensino" (Mathematical Knowledge for Teaching). Os autores subdividiram a categoria definida por Shulman em duas categorias, o conhecimento do conteúdo e o conhecimento pedagógico do conteúdo, em que cada uma delas está subdividida e é representada na Figura1 a seguir.

\footnotetext{
${ }^{4}$ As traduções dos textos em estrangeiros foram feitas pelos autores desta pesquisa.
} 
Figura 1: Subcategorias definidas por Ball, Thames, Phelps (2008).
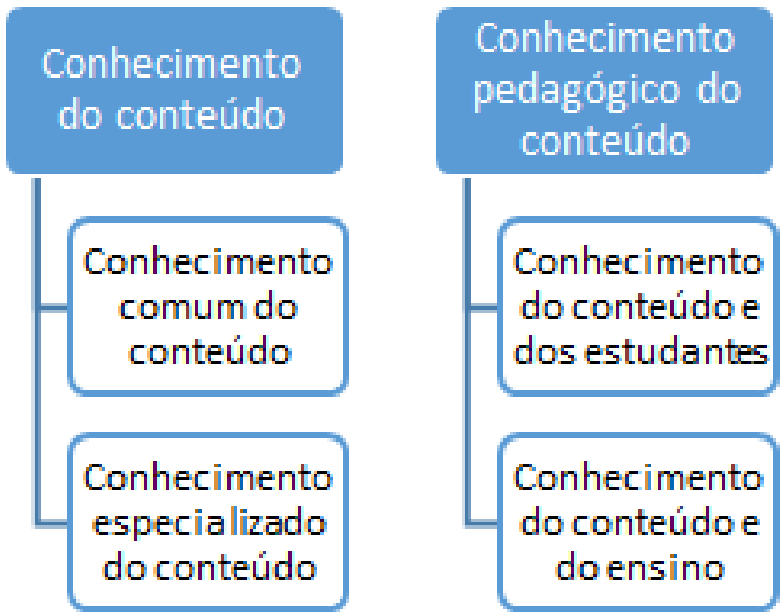

Fonte: Adaptado de Ball, Thames, Phelps (2008).

Seus estudos se basearam na análise da prática de professores, tentando identificar qual é o conhecimento matemático que é necessário para que o professor faça um bom trabalho na sala de aula. E então definiram o conhecimento matemático para o ensino como sendo o conhecimento matemático resultando do processo de ensino, ou seja,

"[...] definimos o conhecimento matemático que estamos estudando como conhecimento matemático "vinculado ao ensino" - em outras palavras, o conhecimento matemático necessário para executar as tarefas recorrentes de ensinar matemática aos alunos." (BALL, THAMES, PHELPS, 2008, p. 399)

O conhecimento comum do conteúdo (common content knowledge (CCK)) está relacionado ao conhecimento que o professor tem no simples fato de resolver um exercício, calcular corretamente um problema matemático, ele compreende o uso correto de notações e termos matemáticos, bem como reconhece respostas de atividades corretas ou incorretas. Esse conhecimento não é exclusivo do ensino, é usado em diferentes contextos, sendo habilidades que outras pessoas também possuem. Segundo Ball, Thames, Phelps (2008, p. 399), "[...] perguntas que exigem saber que um quadrado é um retângulo, que $\frac{0}{7}$ é 0 , e que as diagonais de um paralelogramo não são necessariamente perpendiculares" são exemplos que não requerem um conhecimento especializado, logo podem ser respondidas por outras pessoas que só conhecem a matemática e não necessariamente a estudaram.

O conhecimento especializado do conteúdo (specialized content knowledge (SCK)) está intrinsecamente relacionado ao ensino, é um conhecimento do conteúdo específico ao ensino, não sendo necessário a outros fins ou profissões que não sejam aos de ensinar. São habilidades exclusivas dos professores, por exemplo, distinguir entre as diferentes representações de inequações e saber discorrê-las, da melhor maneira, para os diferentes níveis de ensino. Aqui o professor deve ir além de saber identificar uma questão errada; deve saber qual foi o erro cometido e, porque ele aconteceu; saber avaliar qual algoritmo foi "quebrado" e por quê. Assim o ensino de matemática requer um corpo de conhecimento especializado, visto que

As demandas matemáticas do ensino exigem conhecimento matemático especializado, não necessário em outros contextos. Os contadores precisam calcular e reconciliar números, e os engenheiros precisam modelar matematicamente as propriedades dos materiais, mas nenhum dos grupos precisa explicar por que, quando você multiplica por 10, você "adiciona um zero". (BALL, THAMES, PHELPS, 2008, p. 401) 
Sendo assim, o conhecimento especializado do conteúdo requer um entendimento além do ensinado aos estudantes. Para ensinar, o professor deve dominar além do que está ensinando, deve saber corretamente a linguagem matemática, saber usar diferentes representações para o mesmo conceito. Além de saber, explicar e justificar os conceitos matemáticos, deve fazer adaptações ao conteúdo, discutir sobre as ideias dos estudantes e conseguir sanar as dúvidas deles. Logo o professor precisa ter conhecimento de diferentes representações de um mesmo conceito de modo a fazer os seus estudantes compreenderem o que está sendo estudado.

A categoria conhecimento do conteúdo e alunos (knowledge of content and students(KCS)), relaciona o conhecimento sobre os estudantes e o domínio do conteúdo de Matemática, pois o professor deve conhecer a sua classe ao propor uma atividade e saber se tal atividade será motivadora e interessante ou não. Ele deve prever como seus estudantes irão desenvolvê-la e se a acharão difícil ou fácil, saber interpretar os pensamentos errôneos e incompletos dos seus estudantes e usar a melhor linguagem para fazê-los compreender. De acordo com Ball, Thames, Phelps (2008, p. 401), "Cada uma dessas tarefas exige uma interação entre compreensão matemática específica e familiaridade com os alunos e seu pensamento matemático." Nesse sentido, o professor deve ser capaz de prever quais são os erros corriqueiros cometidos por seus estudantes em determinado tópico e saber quais são suas origens fundamentadas nos conhecimentos sobre o conteúdo.

O conhecimento do conteúdo e ensino (knowledge of content and teaching(KCT)) conecta o conhecimento sobre ensino e o conhecimento sobre o conteúdo de Matemática. De acordo com Ball, Thames, Phelps (2008), o professor deve saber conduzir sua aula, buscando decidir qual é a melhor metodologia para ser usada ao desenvolver determinado conteúdo, fazer uma sequência lógica dos tópicos a serem abordados, quando usar o questionamento de um aluno para suscitar um esclarecimento, saber fazer questionamentos ou perguntas para investigar os estudantes, propor diferentes tarefas de modo a promover a aprendizagem. Essas decisões exigem uma intersecção entre o conhecimento específico do conteúdo e os métodos, e procedimentos de ensino. Para Ball, Thames, Phelps (2008, p. 402), "[...] o conhecimento do ensino e do conteúdo é um amálgama, envolvendo uma ideia ou procedimento matemático específico e familiaridade com os princípios pedagógicos para o ensino desse conteúdo específico."

Ball, Thames, Phelps (2008) expõem que as suas pesquisas em nenhum momento vêm para substituir a teoria do conhecimento pedagógico do conteúdo de Shulman, mas têm um caráter de detalhar os critérios do conhecimento em relação ao assunto para o ensino. Os autores além de detalharem o conhecimento pedagógico do conteúdo, voltam-se para o conhecimento específico da Matemática e revelam diferentes conhecimentos matemáticos necessários para ensinar os conteúdos que não fazem parte do conhecimento pedagógico, os quais são os de estudantes, do currículo e de outras categorias que não o conteúdo. Sendo assim, os professores não devem se debruçar somente sobre o conhecimento específico da Matemática, mas também sobre os demais conhecimentos e assim incorporá-los em suas práticas de ensino.

\section{METODOLOGIA}

Com a definição do objetivo desta pesquisa, delinearam-se algumas concepções metodológicas, que são fundamentais para seu desenvolvimento. Essa pesquisa é classificada como uma abordagem qualitativa, possibilitando uma interpretação dos resultados ricos em particularidades. Para Minayo 
(2015) a pesquisa qualitativa traz a possibilidade de estudo do universo de significados, trabalhando as questões que não podem ser quantificadas como motivos, aspirações, crenças, valores e atitudes.

Esse conjunto de fenômenos humanos é entendido aqui como parte da realidade social, pois o ser humano se distingue não só por agir, mas por pensar sobre o que faz e por interpretar suas ações dentro e a partir da realidade vivida e partilhada com seus semelhantes. (MINAYO, 2015, p. 21)

As pesquisas qualitativas têm como dados as vivências e as experiências do cotidiano, e, nesse sentido, a linguagem, a prática e as relações são inseparáveis. As pesquisas não se preocupam em quantificar seus dados, e sim, em compreendê-los e interpretá-los a partir da realidade vivenciada.

Faz-se importante destacar aqui que foi necessário fazer modificações tanto no problema de pesquisa, e com isso nos objetivos, quanto na metodologia, devido ao momento em que o mundo está passando. Com a pandemia do novo Coronavírus (COVID-19), as escolas da Educação Básica não estão tendo aulas presenciais, muitas inclusive estão dando aulas de forma remota, mas com diversas dificuldades. Logo se buscou direcionar a pesquisa para a realidade que estamos vivenciando atualmente.

Para o levantamento de dados desta pesquisa, foram utilizados dois questionários, sendo um desenvolvido no Formulário Google, em que os professores responderam on-line, e o segundo foi encaminhado por e-mail. Aqui traremos um recorte do segundo questionário, que tinha como objetivo verificar quais são os conhecimentos matemáticos para o ensino de inequações que os professores mobilizam para resolver as atividades sobre inequação.

A pesquisa foi desenvolvida com um grupo de professores de matemática. Eles foram escolhidos de forma aleatória, sendo alguns professores vinculados ao Programa de Pós-Graduação em Ensino de Ciências e Matemática da Universidade Franciscana de Santa Maria, outros que a pesquisadora tinha contato, devido a sua vida acadêmica bem como sua atuação profissional, e os demais, indicações dos próprios professores convidados a serem participantes da pesquisa. Este tipo de amostragem é considerado por conveniência o qual os membros da amostra são escolhidos por proximidades ou pela facilidade de acesso, esse tipo de amostragem é usado quando se torna impossível testar uma categoria inteira.

No primeiro momento foi encaminhado o $1^{0}$ questionário (Apêndice A) aos 27 contatos que a pesquisadora possuía. Este questionário foi criado no Formulário Google, sendo disponibilizado de modo on-line via e-mail e/ou WhatsApp. Ele foi composto por perguntas abertas e perguntas fechadas.

O $1^{\circ}$ questionário foi respondido por 19 professores. A esses foi encaminhado o $2^{\circ}$ questionário (Apêndice B), o qual foi elaborado com atividades sobre inequações. Dos 19 participantes que responderam o $1^{\circ}$ questionário, apenas 10 responderam o $2^{\circ}$ questionário, e assim contribuíram com a pesquisa. E como não temos o intuito de identificar os participantes da pesquisa, eles foram nomeados com um código alfanumérico. Esse código é constituído pela letra $\mathrm{P}$ (de participante) e por um número, correspondente à ordem em que as respostas foram devolvidas pelos participantes, como, por exemplo: P1 corresponde às respostas do primeiro participante que fez a devolutiva do último questionário, P2 do segundo participante, e assim sucessivamente.

O processo de análise de dados foi realizado a partir dos dados coletados pelos questionários encaminhados aos professores, os quais são referentes ao conteúdo de inequações. Para análise dos 
dados, foram desenvolvidas algumas categorias pela pesquisadora, considerando àquelas, propostas por Ball, Thames e Phelps (2008). As categorias são as seguintes:

- conhecimento comum do conteúdo;

- conhecimento especializado do conteúdo;

- conhecimento do conteúdo e do ensino;

Em cada uma dessas categorias, Ball, Thames, Phelps (2008) sugerem algumas características necessárias ao professor, e é a partir dessas características que foram analisados os conhecimentos para o ensino identificado nas resoluções de atividades relativas às inequações. Considerando as características de cada uma das categorias, foram considerados alguns critérios de análise, conforme descrito no Quadro 1.

Quadro 1: Critérios de análise.

\begin{tabular}{|l|l|}
\hline \multicolumn{1}{|c|}{ Categorias analisadas } & \multicolumn{1}{c|}{ Critérios de análise } \\
\hline Conhecimento comum do conteúdo & $\begin{array}{l}\text { Resolução correta das atividades (RC); } \\
\text { Reconhecer resposta errada (RE). }\end{array}$ \\
\hline Conhecimento Especializado do Conteúdo & $\begin{array}{l}\text { Uso da linguagem matemática correta (LM); } \\
\text { Abordagem de diferentes representações (DR); } \\
\text { Reconhecer a natureza do erro (NE); } \\
\text { Ideia matemática clara (IC). }\end{array}$ \\
\hline Conhecimento do Conteúdo e do Ensino & $\begin{array}{l}\text { Estratégias de ensino (EE); } \\
\text { Abordagem de diferentes tarefas (DT); } \\
\text { Desenvolvimento de questões adequado ao ano de } \\
\text { ensino (DA). }\end{array}$ \\
\hline
\end{tabular}

Fonte: Autores (2020).

O entendimento de que uma resposta, de uma determinada questão, se inclui em uma determinada categoria, se deve à identificação dos critérios de análises previstos para essa.

\section{RESULTADOS E DISCUSSÕES}

Esta pesquisa utilizou dois questionários com o intuito de coletar dados. O primeiro questionário visou fazer um levantamento do perfil dos participantes da pesquisa, bem como compreender suas concepções iniciais sobre o tema inequações. O segundo foi formado por questões sobre inequações e o desenvolvimento de uma sequência didática, a qual tinha um roteiro para o seu desenvolvimento. Ele teve o objetivo de verificar os conhecimentos dos professores em relação às inequações. Para este artigo, optamos por apresentar a análise das primeiras quatro questões do segundo questionário desenvolvidos pelos professores de matemática.

As respostas obtidas pelos instrumentos de coleta de dados foram lidas, tabeladas e registradas, constituindo-se nos dados desta pesquisa. Para o tabelamento e registro dos dados, usaram-se as categorias de análise e os critérios descritos no Quadro 1.

A seguir, tem-se a primeira questão proposta aos professores, a qual possui o seguinte enunciado, indicado na Figura 2. 
Figura 2: Questão 1.

1) Observe as seguintes inequações e determine o conjunto solução de cada uma delas. Apresente o desenvolvimento que você realizou para obter o resultado.

\begin{tabular}{|l|}
\hline a) $3(x-7) \geq 4 x+1$ \\
\hline b) $(-4 x+12)(3 x+27)<0$ \\
\hline c) $\frac{2 x+18}{6 x+3} \leq 0$ \\
\hline d) $2 x-10 \leq-x+2<x-3$ \\
\hline
\end{tabular}

Fonte: Autores (2020).

Nas atividades da questão 1 , os professores deveriam fazer a solução das inequações propostas. A atividade $\boldsymbol{a}$ representa uma inequação do primeiro grau, a atividade $\boldsymbol{b}$ uma inequação-produto, a $\boldsymbol{c}$ uma inequação-quociente e a $\boldsymbol{d}$ uma inequação-simultânea. As atividades têm formas distintas para serem resolvidas.

Na letra $\boldsymbol{a}$ ) da questão 1 , todos os professores resolveram corretamente e fazendo uso adequado da linguagem matemática, demonstrando conhecimento do conteúdo de inequações. Destacam-se aqui dois professores (P2 e P5) que, além de resolverem algebricamente, também representaram a solução da inequação graficamente, sendo que, para chegar ao resultado, não era preciso utilizar o gráfico. $\mathrm{A}$ Figura 3 mostra a resposta do professor P2.

Figura 3: Resposta do professor P2 na letra a da questão 1.

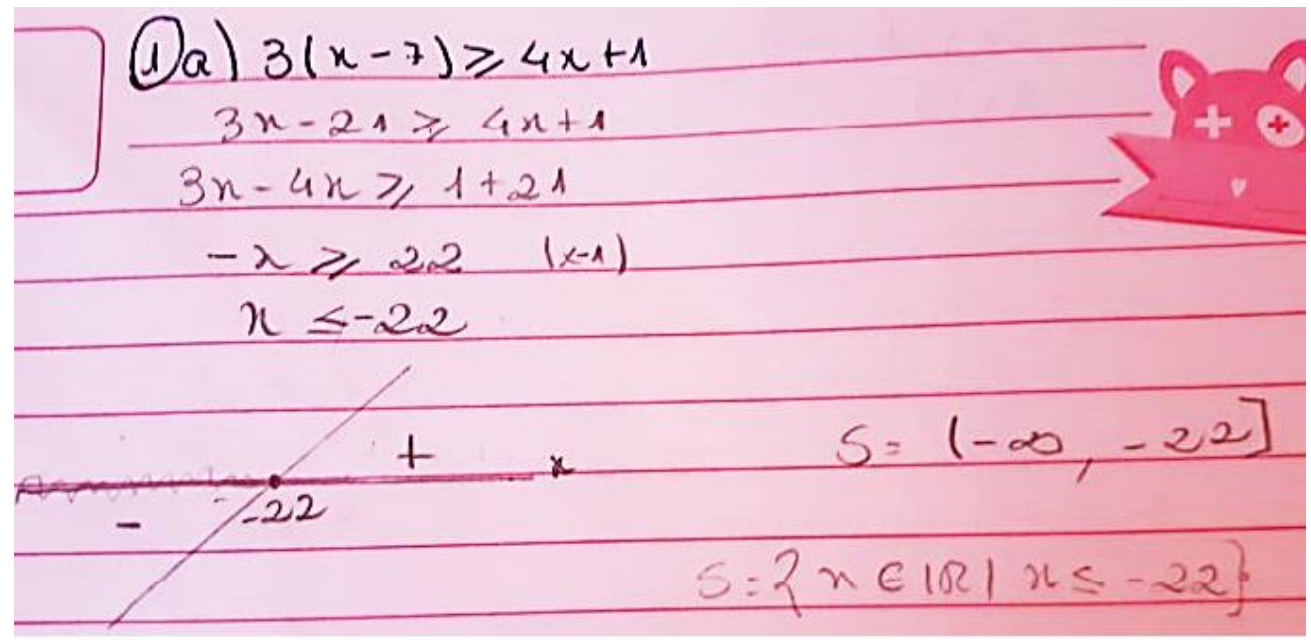

Fonte: Dados da pesquisa (2020).

Primeiramente a professora P2 aplicou a propriedade distributiva da multiplicação e, após usou as propriedades elementares para obter o resultado. Ela obteve o conjunto solução desta inequação, representou na linguagem matemática correta de duas maneiras, e optou por fazer a representação gráfica.

A atividade $\boldsymbol{b}$ estava relacionada com uma inequação-produto. Todos os professores resolveram corretamente e fizeram uso adequado da linguagem matemática. Entretanto, ao se tratar de ensino de inequações para o Ensino Fundamental - Anos Finais, quatro professores, P1, P5, P6 e P7, não executaram o desenvolvimento da questão de forma adequada ao ano de ensino (DA), pois a resolveram através da equação do segundo grau, conforme ilustrado na Figura 19. 
Figura 4: Resposta do professor P6 na letra b da questão 1.

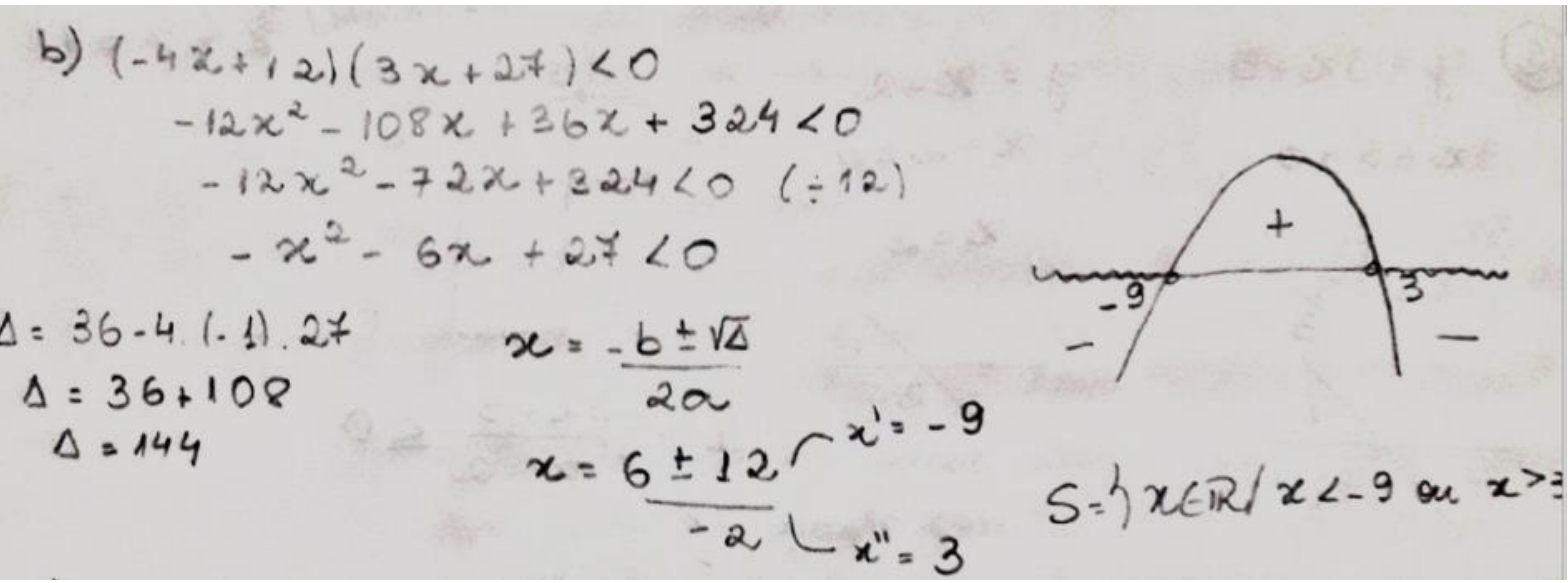

Fonte: Dados da pesquisa (2020).

O professor P6 aplicou a propriedade distributiva da multiplicação, chegando a uma inequação do segundo grau. Resolveu a equação do segundo grau, usando a fórmula de Bhaskara e após fez o gráfico e o estudo dos sinais, para então chegar ao conjunto solução. Os demais professores resolveram de forma adequada para o ensino nos Anos Finais do Ensino Fundamental. Primeiramente separaram as expressões, transformando em duas equações, e após fizeram os gráficos e o estudo dos sinais, considerando a desigualdade, conforme apresenta na Figura 5.

Figura 5: Resposta do professor P3 na letra b da questão 1.

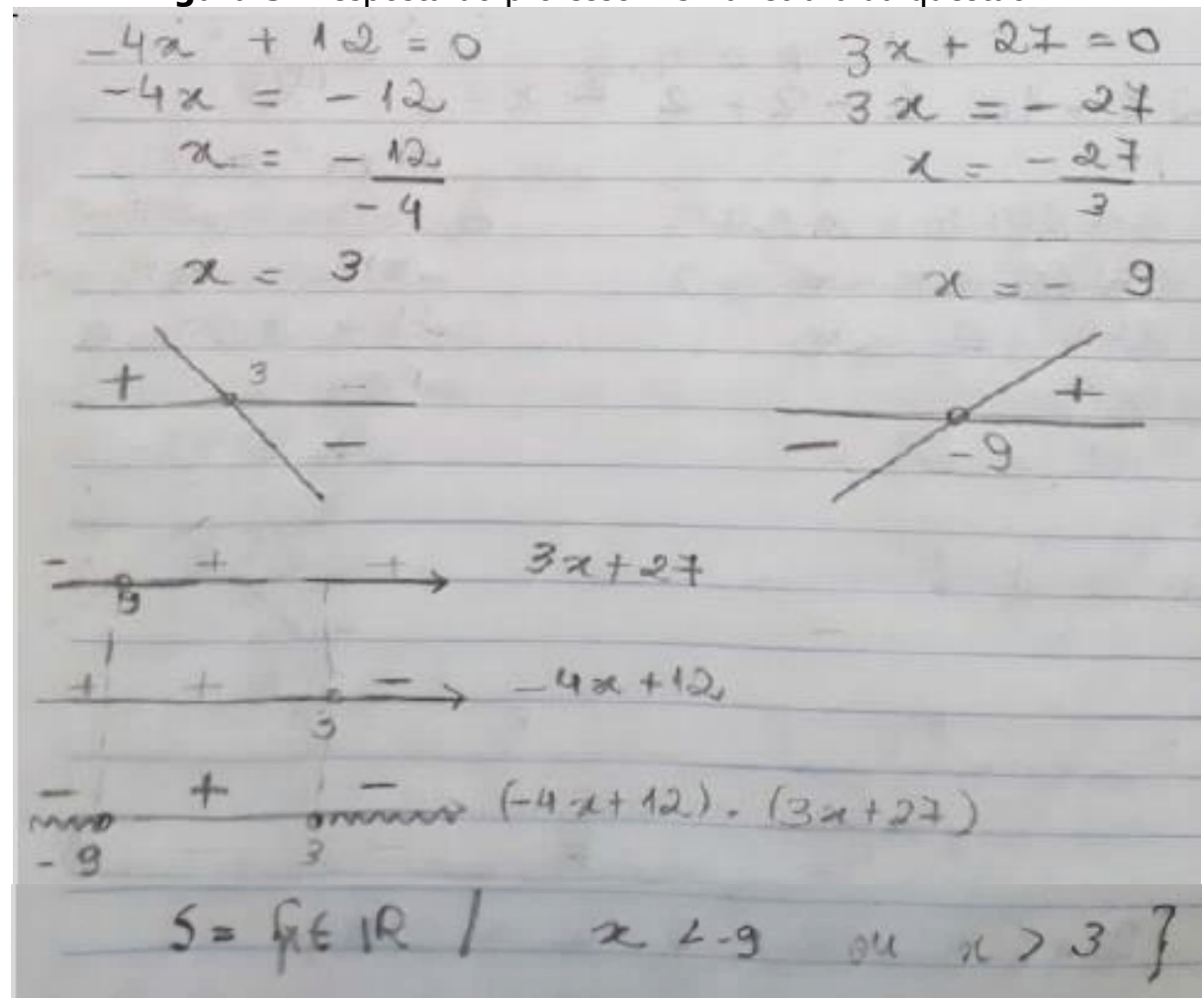

Fonte: Dados da pesquisa (2020).

A atividade $\boldsymbol{c}$ representava uma inequação-quociente, a qual todos os professores resolveram corretamente e fizeram uso da linguagem matemática correta, além de resolverem de forma adequada para o ano de ensino em questão. Na Figura 6, pode ser verificada a forma com que esta questão foi desenvolvida pelo professor P4, a que se aproxima da forma como os demais professores resolveram. 
Figura 6: Resposta do professor P4 na letra c da questão 1.

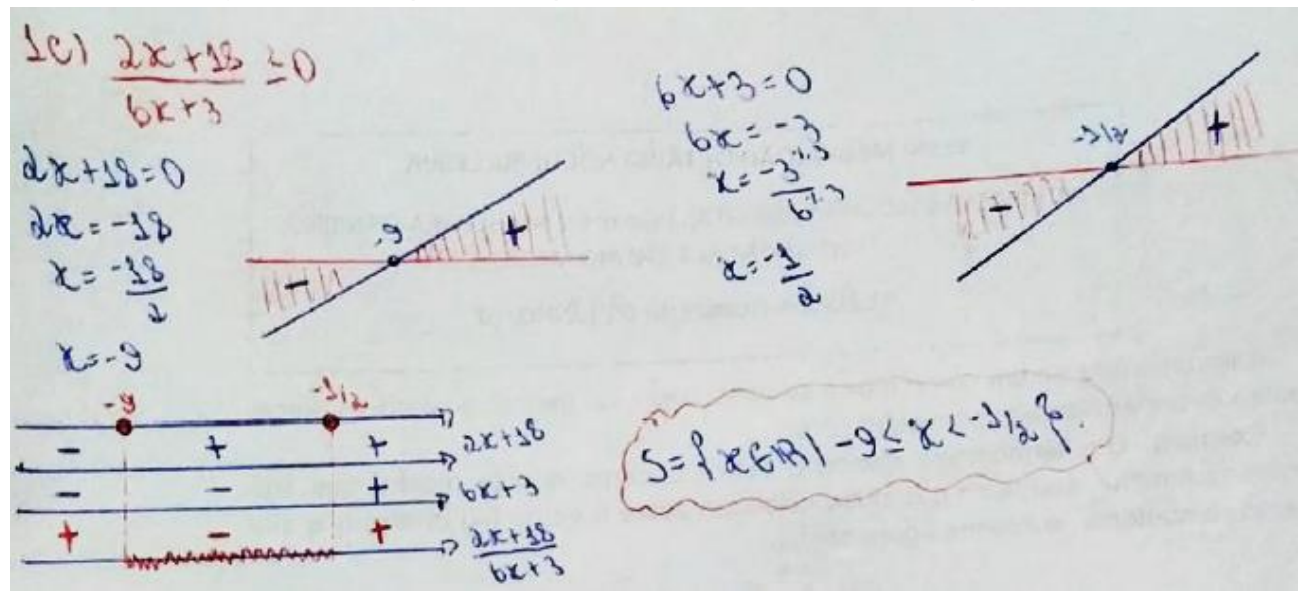

Fonte: Dados da pesquisa (2020).

O professor P4 transformou a inequação-quociente em duas equações do primeiro grau, resolveu-as, usando as propriedades e após fez o gráfico de cada equação. Por fim, fez o estudo de sinais para encontrar o conjunto solução da inequação. Sem o estudo da parte gráfica das atividades $\boldsymbol{b}$ e $\boldsymbol{c}$, os professores não conseguiriam chegar no conjunto solução destas inequações.

A atividade $\boldsymbol{d}$ da questão 1 representa um inequação-simultânea, a qual todos os professores fizeram a resolução de forma correta e adequada ao ano de ensino em questão. A Figura 7 ilustra a forma com que os professores resolveram esta atividade.

Figura 7: Resposta do professor P4 na letra d da questão 1.

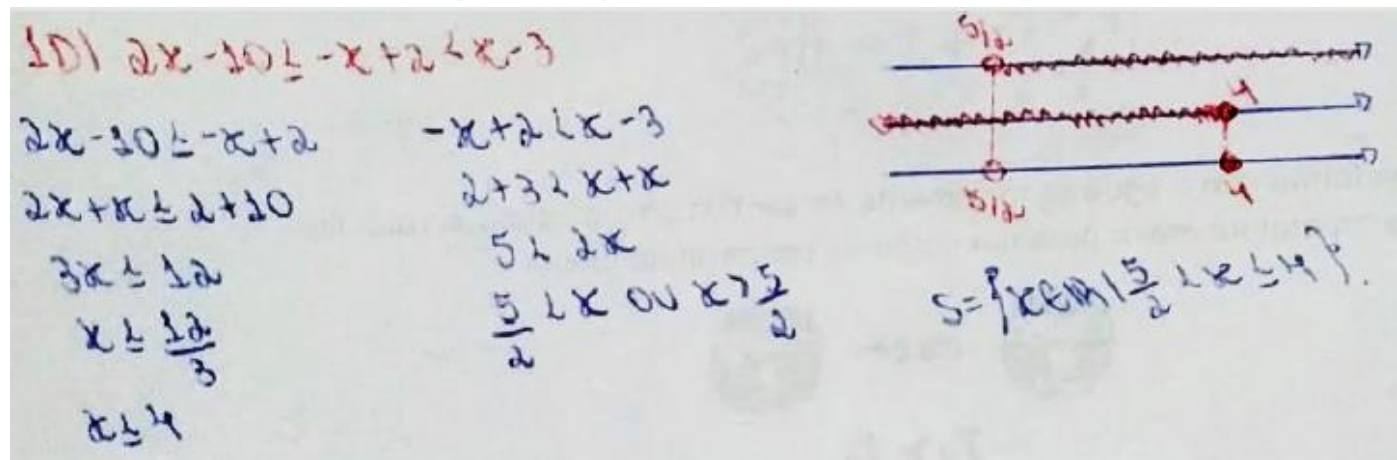

Fonte: Dados da pesquisa (2020).

Como se observa na resposta acima, os professores primeiramente, separaram a inequaçãosimultânea em duas inequações do primeiro grau, e após usaram as propriedades da desigualdade para resolvê-las. Por último, fizeram os gráficos das equações do primeiro grau e o seu estudo, e assim definiram o conjunto solução da inequação-simultânea. Para essa inequação, como as duas anteriores, também se faz necessária uma abordagem gráfica para a conclusão do conjunto solução.

Observando as respostas dos professores à questão 1, constata-se que eles têm o conhecimento comum do conteúdo, o qual, segundo Ball, Thames, Phelps (2008), são conhecimentos e habilidades que não são exclusivos ao ensino, sendo que qualquer pessoa pode resolver uma determinada conta se conhece seu algoritmo. Todos os professores fizeram uso adequado da linguagem matemática, mesmo alguns não levando em consideração os anos de ensino deste conteúdo e fazendo o seu desenvolvimento, de forma que ficaria difícil de abordar-se nos Anos Finais do Ensino Fundamental. 
Destaca-se também o uso da representação gráfica pela maioria dos professores, que a utilizaram apenas quando necessário, para chegar ao conjunto solução das inequações, como, por exemplo, nas atividades $\boldsymbol{b}, \boldsymbol{c}$ e $\boldsymbol{d}$, uma vez que na atividade $\boldsymbol{a}$, em que não havia a necessidade da representação gráfica para descrever o conjunto solução, apenas dois professores resolveram. Segundo Rezende e Travassos (2018), é importante usar diferentes representações para um mesmo conceito, pois isso ajuda o estudante a ter uma melhor compreensão do objeto matemático.

Em relação aos demais conhecimentos para o ensino, percebem-se indícios do conhecimento especializado do conteúdo e do conhecimento do conteúdo e do ensino, pois, além de fazerem a resolução correta das atividades, os professores também fizeram uso da linguagem matemática correta e usaram abordagens de diferentes representações.

A segunda questão proposta aos professores está relacionada com a análise de um gráfico, como pode ser observado na Figura 8.

Figura 8: Questão 2.

2) Determine a inequação quociente que tem como solução os valores de $\mathrm{x}$ compreendidos na área hachurada do gráfico baixo.

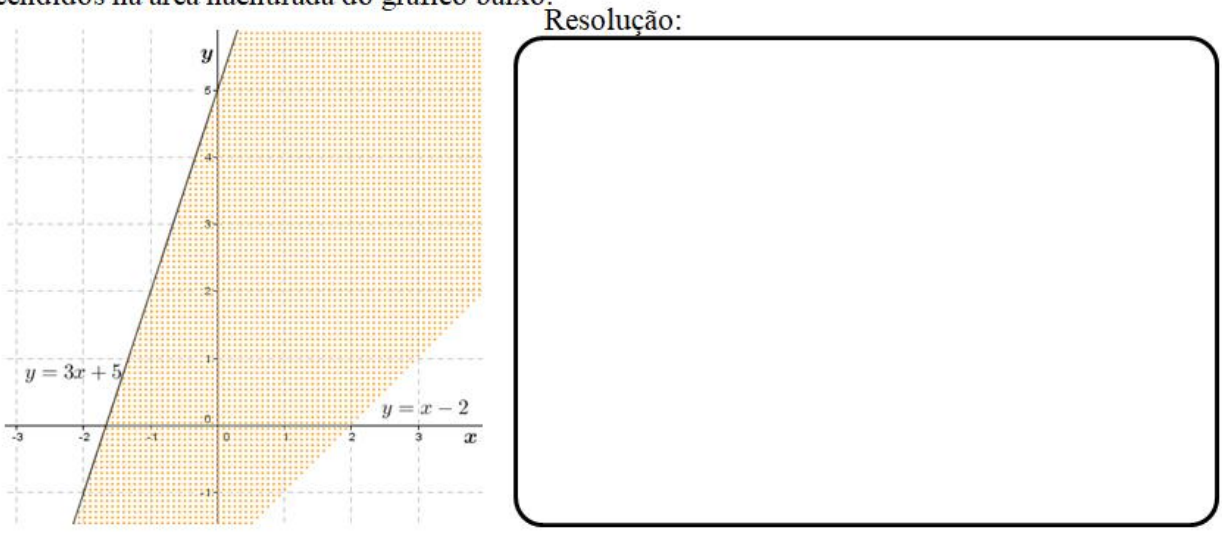

Fonte: Autores (2020).

Esta questão apenas 3 professores, P1, P6 e P7, desenvolveram corretamente. Quatro não responderam, e os demais equivocaram-se nas suas respostas, o que demonstrou que os professores não conseguiram compreender e analisar o gráfico proposto, demonstrando uma fragilidade no conhecimento referente à linguagem gráfica. Como se pode observar na Figura 8 há uma reta que está limitando a área hachurada, no lado esquerdo, que é a reta $y=3 x+5$, ela está contida nesta área, e delimitando o lado direito, tem a reta $y=x-2$, que não faz parte desta área. A Figura 9 mostra o desenvolvimento do professor P6 nesta questão.

Figura 9: Resposta do professor P6 na questão 2.

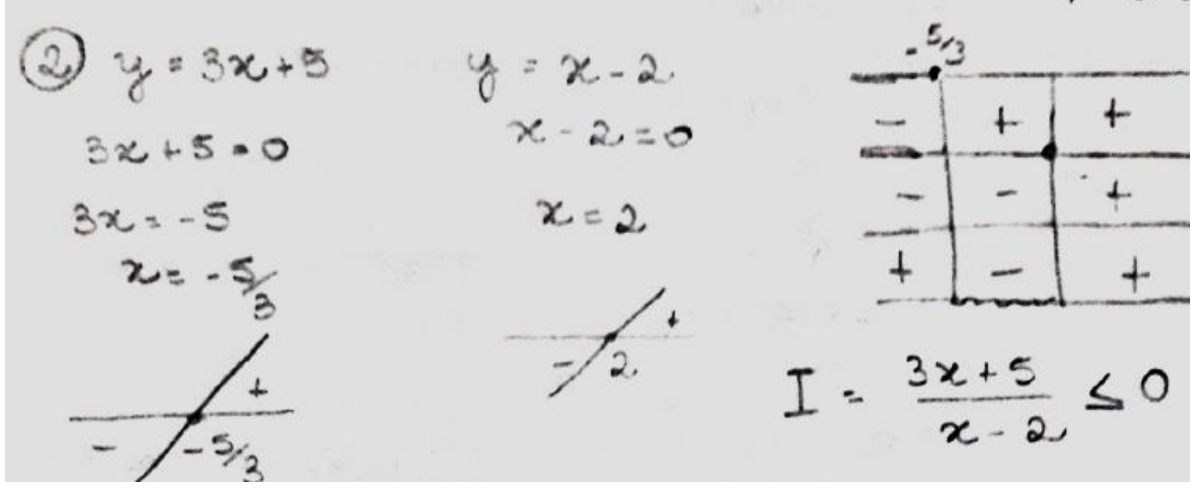

Fonte: Dados da pesquisa (2020). 
Podemos observar que primeiramente o professor resolveu cada função do primeiro grau e fez suas respectivas representações gráficas. Após, ele montou o quadro de estudo dos sinais, e, como ele queria a área compreendida entre $-\frac{5}{3}$ e 2 , ele concluiu que a inequação-quociente é $\frac{3 x+5}{x-2} \leq \mathbf{0}$. Os outros dois participantes que desenvolveram corretamente esta questão também fizeram este mesmo caminho para chegar à inequação-quociente representada no gráfico. A Figura 10 aborda uma das respostas erradas.

Figura 10: Resposta do professor P2 na questão 2.

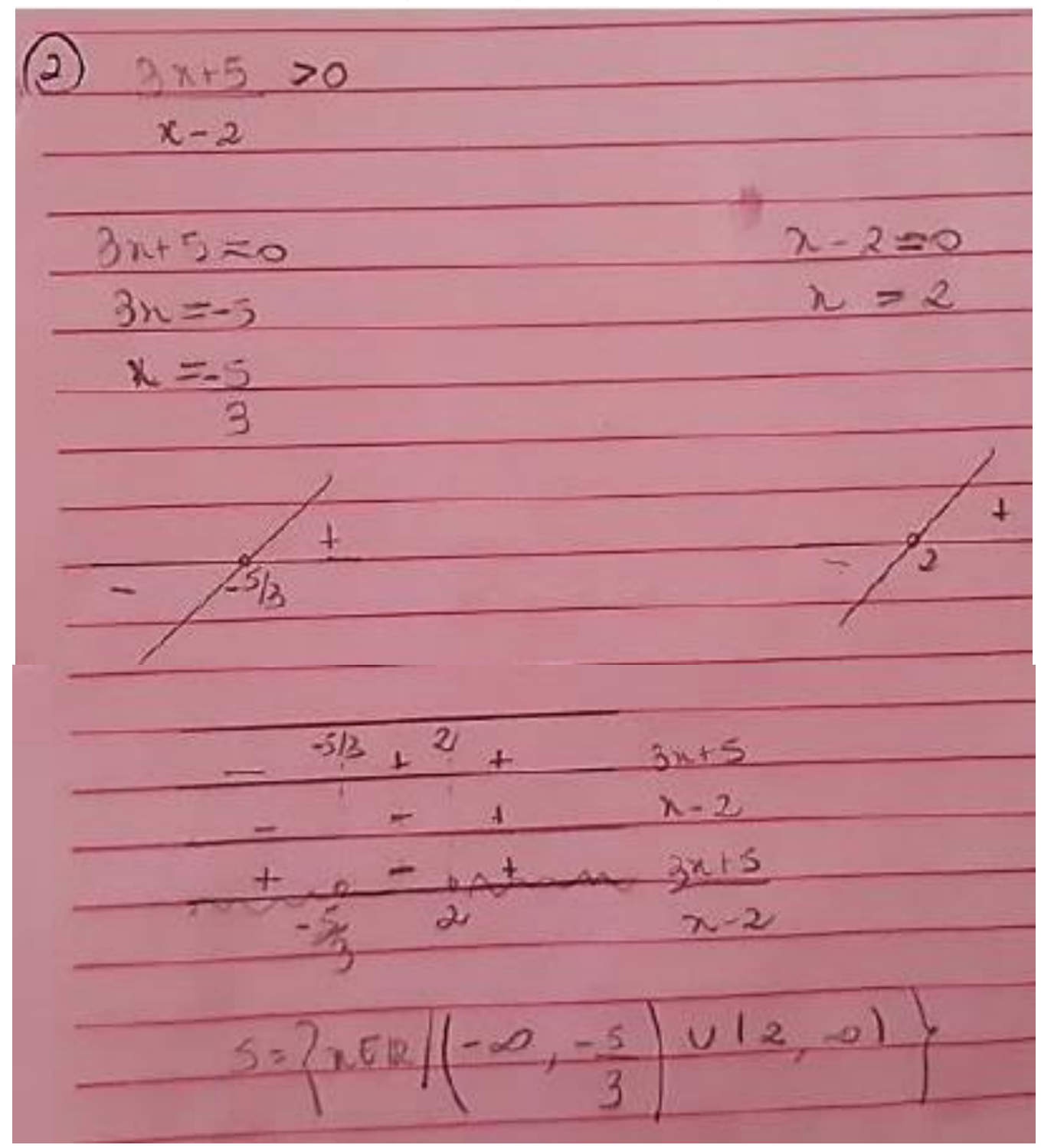

Fonte: Dados da pesquisa (2020).

Em relação à Figura 10, podemos observar que o professor se equivocou, quando analisou o quadro de sinais e o gráfico proposto, pois ele desenvolveu corretamente a atividade, porém, quando definiu a inequação-quociente, ignorou que a área hachurada seria a compreendida entre $0-\frac{5}{2}$ e 2 logo, a inequação-quociente seria menor ou igual a zero e não maior do que zero. O mesmo aconteceu com o professor P3. Já o participante P4 também realizou o desenvolvimento da questão de forma adequada, mas ignorou o gráfico inicial, pois não considerou que a reta $y=3 x+5$ estava contida na área hachurada e que a reta $\mathrm{y}=\mathrm{x}-2$ não estava contida, logo o denominador só poderia ser a reta $x-2$. A Figura 11 demonstra o equívoco. 
Figura 11: Resposta do professor P4 na questão 2.

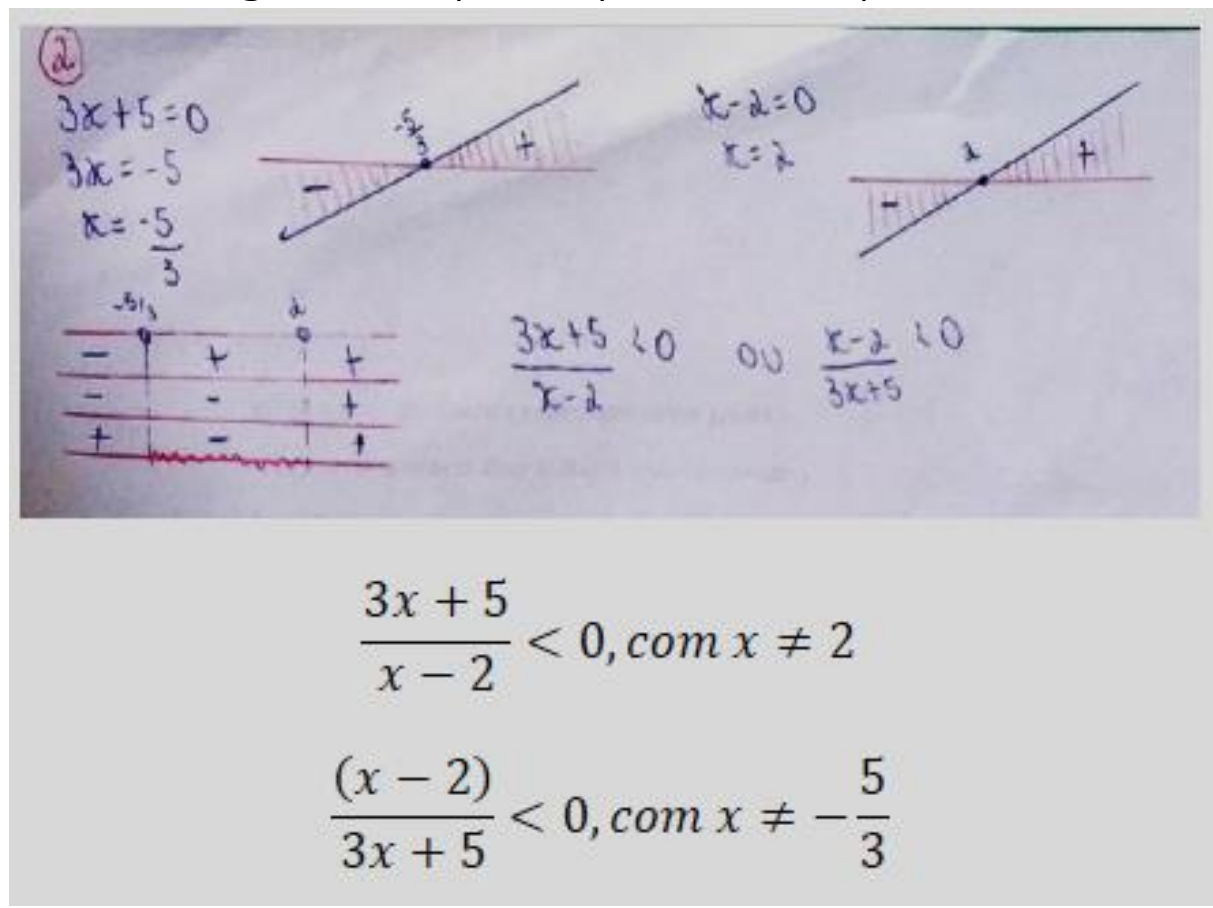

Fonte: Dados da pesquisa (2020).

Ainda em relação a esta questão, os demais professores não a responderam, o que demonstra que há uma fragilidade no conhecimento de outras representações, principalmente quando as questões não abordam as representações da forma convencional - conversão da linguagem algébrica para a linguagem gráfica. Nos próprios livros analisados, destaca-se a pouca ou nenhuma abordagem de representações gráfica. Nesse mesmo sentido, Rezende e Travassos (2018) destacam, no seu estudo, a carência da conversão entre os registros de representações nas obras, por eles analisadas, e assim sugerem aos professores complementarem suas aulas, buscando outros livros e materiais a fim de propiciar e articular experiências entre as diferentes representações e diferentes registros.

Na terceira questão, os professores deveriam elaborar um problema que teria como solução o gráfico fornecido, conforme ilustrado na Figura 12.

Figura 12: Questão 3.

3) Elabore um problema que tenha como solução o gráfico abaixo.

Problema:

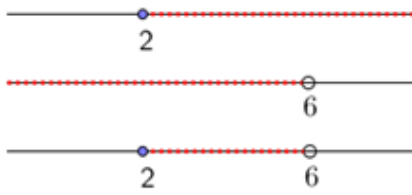

Fonte: Do autor (2020).

Esta atividade três professores não a desenvolveram, e, dentre aqueles que completaram a atividade, seis fizeram situações-problema, e um abordou algebricamente a situação indicada pelo gráfico, usando o seguinte enunciado "Das opções abaixo, qual é o intervalo de $A=\{x \in \mathbb{R} / 2 \leq x<6\}$ ?. 
Acredita-se que o professor P9 pensou em usar outras representações gráficas parecidas com a inicial, e assim usar a inicial como correta, ou ainda pensou em três retas distintas e que a terceira reta seria a que representaria o intervalo descrito. Logo, a resposta dada pelo professor à atividade três não ficou clara.

Dos participantes que fizeram situações-problema, três usaram a interpretação gráfica com a linguagem natural. A Figura 13 ilustra a resposta do professor P6. Os professores P1 e P7 também desenvolveram seus problemas, usando ideias análogas.

Figura 13: Resposta do professor P6 na questão 3.

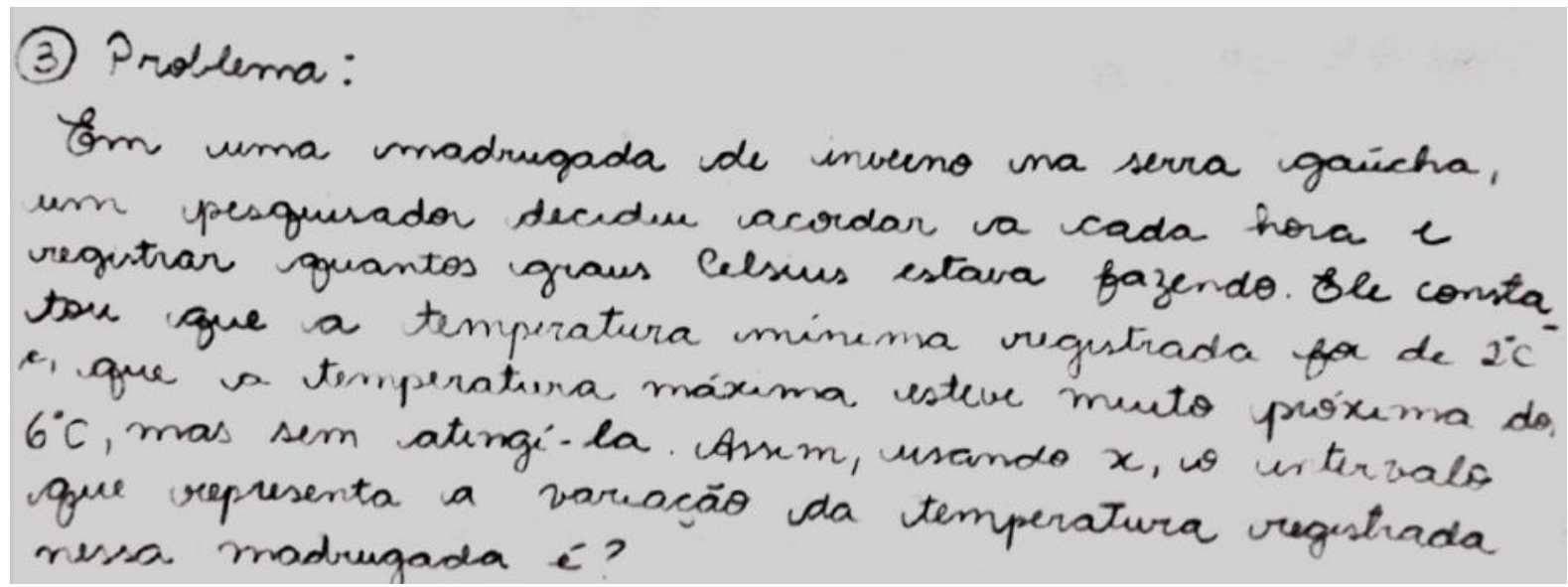

Fonte: Dados da pesquisa (2020).

Os outros três participantes, P2, P3, e P4, desenvolveram uma situação-problema, propondo uma situação na linguagem natural, a qual deve ser traduzida para a linguagem algébrica e tem como solução o gráfico sugerido. Na Figura 14, é possível ver a resposta do professor P4, os outros dois participantes desenvolveram o problema usando ideias similares.

Figura 14: Resposta do professor $P 4$ na questão 3

Em uma cidade do interior do Rio Grande do Sul, três empresas prestam serviços de táxi, segundo a prefeitura, os valores de cada empresa estão apresentados no quadro abaixo:

\begin{tabular}{|l|l|l|}
\hline Empresa & Custo Fixo & $\begin{array}{l}\text { Custo adicional por } \\
\mathrm{km}\end{array}$ \\
\hline 1 & $R \$ 6,00$ & $R \$ 9,00$ \\
\hline 2 & $R \$ 12,00$ & $R \$ 6,00$ \\
\hline 3 & $R \$ 24,00$ & $R \$ 4,00$ \\
\hline
\end{tabular}

Para quais valores a empresa 1 possui preço maior ou igual que a empresa 2 e a empresa 2 possui valor menor que a empresa 3?

Fonte: Dados da pesquisa (2020).

Analisando as questões dois e três, observa-se que há uma fragilidade no conhecimento especializado do conteúdo, no que se refere à representação gráfica. Uma vez que na questão 2 apenas três participantes responderam corretamente, já na questão três, quatro professores não responderam. Para Ball, Thames, Phelps (2008), o conhecimento especializado do conteúdo é aquele conhecimento em que o professor deve saber diferentes algoritmos, assim como utilizar diferentes abordagens para ensinar um mesmo conteúdo. A carência deste conhecimento em relação à parte gráfica, pode prejudicar o processo de ensino e aprendizagem, logo ele pode não ocorrer de maneira eficaz. 
A quarta questão aborda duas situações para as quais os professores deveriam criar questionamentos que abordassem o conteúdo de inequações. A questão pode ser observada na Figura 15.

Figura 15: Questão 4.

4) Levando em consideração as duas situações abaixo, crie questionamentos que explorem o conteúdo de inequação.

Situação 1:

Ao fazer uma festa de aniversário de três anos, Elis convidou mais meninas que meninos. Mesmo faltando 4 meninas convidadas, o número de meninas ainda era maior que o de meninos, que era 8.

Que questionamentos você poderia elaborar com os dados apresentados?

Situação 2:

Natalia está organizando uma festa de 30 anos para sua amiga. Para a festa ela irá
contratar um disc jockey (DJ). Para a contratação ela fez uma pesquisa com três
empresas que disponibilizam este serviço, os valores estão representados no quadro
abaixo.
\begin{tabular}{|c|c|c|}
\hline Empresa & Custo fixo & Custo adicional por hora \\
\hline 1 & RS 100,00 & RS 20,00 \\
\hline 2 & RS 55,00 & RS 35,00 \\
\hline 3 & RS 0 & RS 43,00 \\
\hline
\end{tabular}

Que questionamentos você poderia elaborar com os dados apresentados?

Fonte: Dados da pesquisa (2020).

Em relação à situação 1, todos os professores responderam. Os questionamentos que apareceram, em todas as respostas, foi uma variação na linguagem natural de "Quantas meninas, no mínimo Elis convidou?". Tiveram outros questionamentos como: "Podemos saber quantas meninas Elis convidou para sua festa?". Estes questionamentos são frágeis para serem trabalhados em inequação, pois o estudante não necessariamente precisa montar uma inequação para resolvê-los, uma vez que ele pode simplesmente responder que o mínimo de meninas convidadas é 13, fazendo um cálculo mental de $9+4$. Os professores P4, P5 e P9 fizeram também outros questionamentos, como, por exemplo: "como poderia ser representado esta situação por meio de uma inequação", e, logo após, questionar o número de meninas que teria na festa. A professora P10 faz questionamentos interessantes, levando o estudante a representar cada linha algebricamente, conforme ilustrado na Figura 16. 
Figura 16: Resposta do professor P10 na questão 4 situação 1.

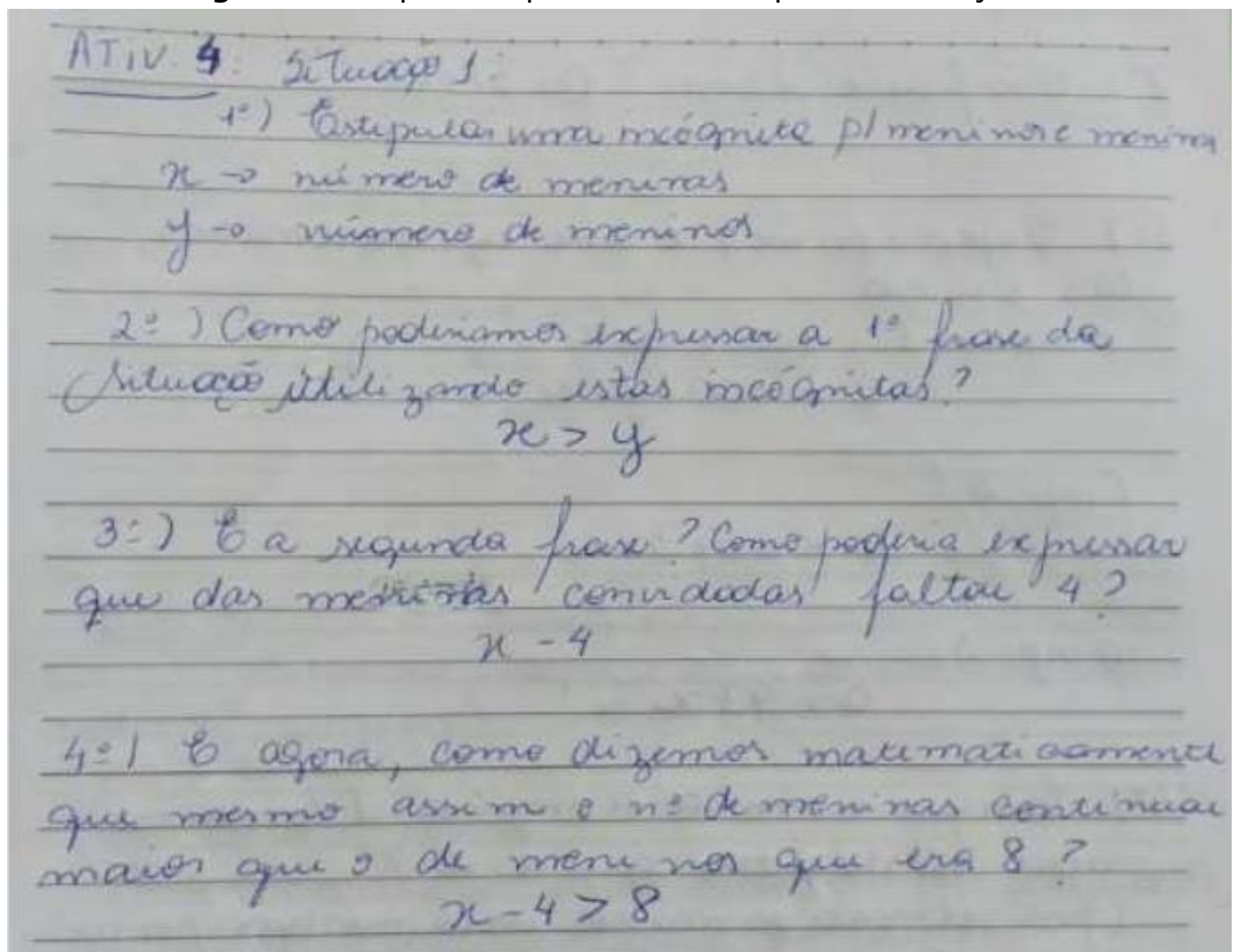

Fonte: Dados da pesquisa (2020).

Na situação 2, os professores P1, P2, P3, P4, P5 e P10 usaram questionamentos nos quais os estudantes devem montar uma inequação, questionando, por exemplo: " $A$ partir de quantas horas a empresa 1 é mais barata que a empresa 2?". Conforme demonstrado pela resposta do professor P4 na Figura 17.

Figura 17: Resposta do professor P4 na questão 4 situação 2

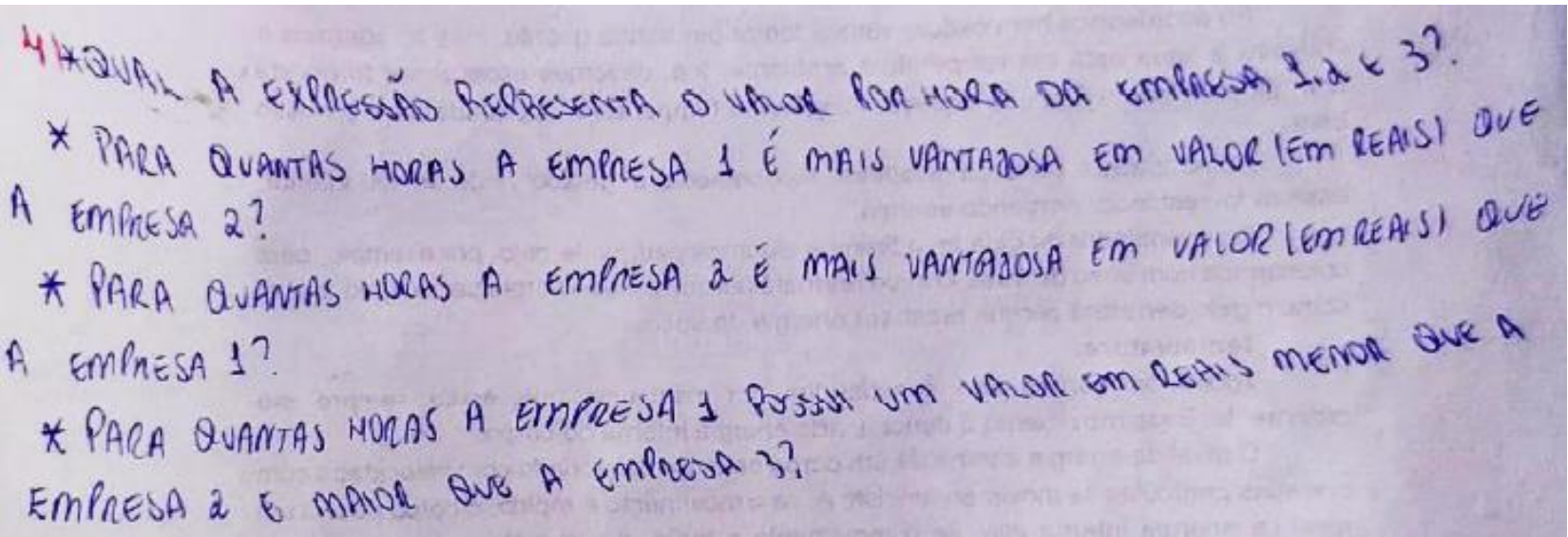

Fonte: Dados da pesquisa (2020).

Em relação a esses tipos de questionamentos, acima representados, a professora P10 destaca que os estudantes ainda assim poderiam resolver por meio de cálculos, logo finalizaria com a seguinte pergunta: "Como poderíamos expressar esta situação por meio de uma inequação?"

Os professores P6 e P7 desenvolveram esta situação, porém entendemos que eles não contemplaram o conteúdo de inequações, como, por exemplo, a resposta do professor P7, representada na Figura 18 , e os questionamentos do professor P6 seguem essa mesma ideia. 
Figura 18: Resposta do professor P7 na questão 4 situação 2

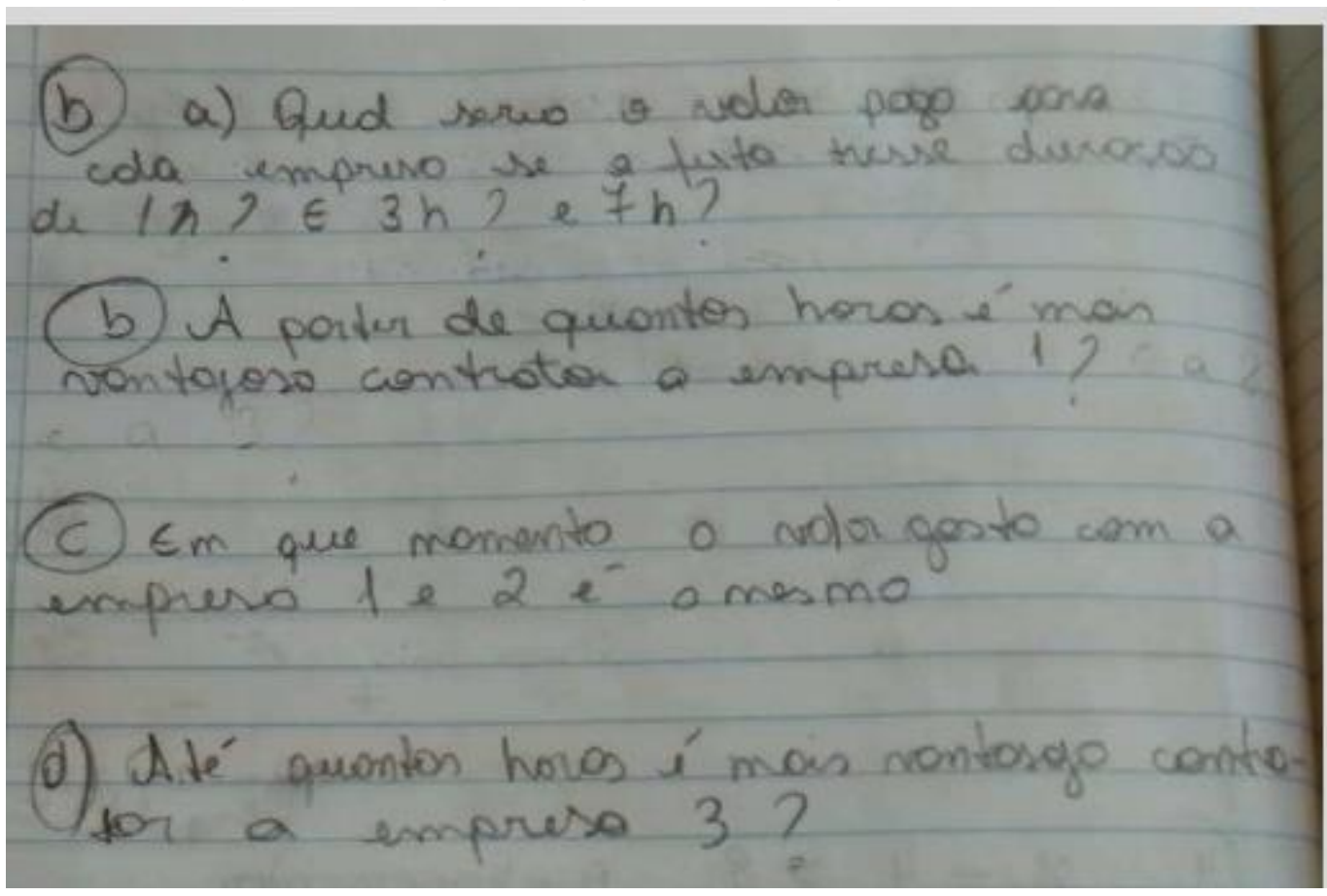

Fonte: Dados da pesquisa (2020).

Os questionamentos destacados na Figura 18 podem ser resolvidos, como mencionado pelo professor P10, através de cálculos. Eles não exigem dos estudantes o desenvolvimento de uma inequação, ao responderem o questionamento $\boldsymbol{a}$, os estudantes provavelmente usariam sua resposta para resolver os demais questionamentos.

Em relação à questão 4, observa-se que a maioria dos professores possuem o conhecimento do conteúdo e do ensino, pois, para Ball, Thames, Phelps (2008, pg. 401), esta categoria está associada como "Os professores sequenciam um conteúdo específico para obter instruções. Eles escolhem quais exemplos para começar e quais exemplos usar para levar os alunos mais a fundo no conteúdo." $\mathrm{O}$ que vem ao encontro com o que os professores desenvolveram através das situações dadas, que foi criar questionamentos a fim de abordar o conteúdo de inequações. Destaca-se, também, o conhecimento especializado do conteúdo, pois, as ideias matemáticas estavam claras, além de proporem questionamentos que abordaram o conteúdo de inequações, o que demonstra o domínio deste conceito.

\section{CONSIDERAÇÕES FINAIS}

Esta pesquisa foi realizada com 10 professores de matemática, e teve como problema de pesquisa "Quais conhecimentos para o ensino são identificados nas resoluções de atividades sobre inequações, apresentadas por um grupo de professores de Matemática?". A motivação dessa, deu-se por observar as dificuldades que os estudantes têm em relação à Álgebra, além da carência de estudos sobre o ensino de inequações nos Anos Finais do Ensino Fundamental II, fato que não favorece o desenvolvimento do pensamento algébrico.

Nosso referencial teórico baseou-se no conhecimento matemático para o ensino, na Álgebra e no pensamento algébrico. Considerando o conhecimento pedagógico do conteúdo de Shulman (1986, 1987), o qual é um dos pesquisadores referência sobre os conhecimentos e habilidades necessários 
a um professor competente, Ball, Thames, Phelps (2008) basearam-se em suas ideias para então aprofundar o entendimento sobre o conteúdo necessário para o ensino. Tais abordagens permitem investigar a natureza, o papel e os diversos tipos de conhecimentos para o ensino de Matemática, dessa maneira, embasamos nosso estudo nessas ideias, a fim de atingir o objetivo.

Sobre o conhecimento comum do conteúdo, Ball, Thames, Phelps (2008) definem que é o conhecimento comum a qualquer pessoa, e não necessariamente ele precisa ser professor para possuir esse conhecimento, ele não é exclusivo do ensino, mas sim, é utilizado em diferentes contextos, sendo habilidades que outras pessoas também possuem. Verificou-se, portanto, que todos os professores detêm esse conhecimento, pois não demonstraram dificuldades para desenvolver a maioria das questões sobre inequação, além de fazerem o uso adequado da linguagem matemática. Alguns não consideraram os anos de ensino deste conteúdo, e fizeram o desenvolvimento de algumas atividades de forma que dificultaria a sua abordagem nos Anos Finais do Ensino Fundamental, todavia isso não é considerado no conhecimento comum do conteúdo.

Em relação ao conhecimento especializado do conteúdo, alguns professores demonstraram dificuldades nas resoluções das atividades que abordaram a representação gráfica. Tais dificuldades ficaram evidentes quando eles não conseguiram encontrar a inequação correspondente ao gráfico e ao proporem atividades que não condiziam com o gráfico abordado. Dessa maneira, demonstrou-se uma lacuna na abordagem de diferentes representações, logo há uma fragilidade do conhecimento especializado do conteúdo, o qual requer que os professores dominem além do que está sendo ensinado, dominem o uso correto da linguagem matemática, e ainda usem diferentes representações para o mesmo conceito, sabendo explicar e justificar os conceitos matemáticos. Considerado o descrito por Ball, Thames, Phelps (2008), a deficiência desse conhecimento implicará no seu ensino.

Por fim, o conhecimento do conteúdo e do ensino ficou evidente na análise das respostas dos professores, quando propuseram atividades coerentes ao ensino de inequações e ao prepararem uma sequência didática lógica dos tópicos descritos, abordando diferentes tarefas, bem como propondo diferentes estratégias de ensino. Tal fato corrobora com Ball, Thames, Phelps (2008), pois o professor deve saber conduzir sua aula, buscando decidir qual é a melhor metodologia para ser usada ao desenvolver determinado conteúdo, deve também fazer uma sequência lógica dos tópicos a serem abordados, além de fazer questionamentos ou perguntas para investigar os estudantes, propondo assim diferentes tarefas de modo a promover a aprendizagem.

À vista disso, consideramos que há manifestações do conhecimento matemático para o ensino nas respostas dos professores, pois, mesmo não conseguindo identificar todas as categorias descritas por Ball, Thames, Phelps (2008), os professores, de modo geral, tiveram êxito no desenvolvimento das atividades sobre inequações, além do que, foi possível observar as suas facilidades e fragilidades no que se refere ao seu ensino. Verificamos, ainda, que alguns professores possuem dificuldades em transitar entre as diferentes representações de uma inequação, e essas dificuldades podem prejudicar o processo de ensino e aprendizagem. Segundo a BNCC (2018), os estudantes devem transitar entre as diferentes representações algébricas, assim como identificar regularidades e estabelecer leis matemáticas. Nesse sentido, entendemos que, se, os próprios professores têm fragilidades nas representações algébricas, existirão essas mesmas dificuldades no processo de ensino e aprendizagem.

Acredita-se que o trabalho desenvolvido favorece a observação da fragilidade dos professores em alguns conhecimentos para o ensino de inequação, abrindo espaço para novas pesquisas que 
envolvam/proponham formações - inicial e/ou continuada -, no que se refere a diferentes abordagens algébricas. Além disso, concluímos que os resultados emergentes desta pesquisa podem contribuir para ampliar as reflexões em relação à Álgebra, ao pensamento algébrico e à inequação, e assim contribuir para o processo de ensino e aprendizagem, envolvendo tanto professores como estudantes da Educação Básica.

\section{REFERÊNCIAS}

BALL, Deborah Loewenberg. THAMES, Mark Hoover. PHELPS, Geoffrey. Content knowledge for teaching: what makes it special? Disponível em:

http://citeseerx. ist.psu.edu/viewdoc/download?doi=10.1.1.493.2271\&rep=rep1\&type=pdf Acesso em: 10 abr 2020.

BRASIL. Base Nacional Comum Curricular. Brasília: MEC, 2018. Disponível em: http://basenacionalcomum.mec.gov.br/images/BNCC_EI_EF_110518_versaofinal_site.pdf. Acesso em: 02 jun. 2020.

BRASIL. Parâmetros curriculares nacionais. 2. Matemática: Ensino de quinto a oitava série. Secretaria de Educação Fundamental. - Brasília: MEC/SEF, 1998.

FERREIRA, Miriam Criez Nobrega. Álgebra nos Anos Iniciais do Ensino Fundamental: uma análise do conhecimento matemático acerca do Pensamento Algébrico. Santo André: UFABC, 2017. Dissertação (Mestrado), Programa de Pós-Graduação em Ensino, História e Filosofia das Ciências e Matemática, Universidade Federal do ABC, 2017.

FIORENTINI, Dário. MIORIM, Maria Ângela. MIGUEL, Antônio. Contribuição para um Repensar... a Educação Algébrica Elementar. Pro-Posições, vol. 4, n.1[10], 78-91, 1993.

FREIRE, Raquel Santiago. Desenvolvimento de conceitos algébricos por professores dos anos iniciais do Ensino Fundamental. Fortaleza: UFC, 2011. Tese, Programa de Pós-Graduação em Educação Brasileira, Universidade Federal do Ceará, 2011.

MINAYO, M. C. S. (Org.). Pesquisa social: teoria, método e criatividade. Petrópolis, Editora Vozes, 2015.

SHULMAN, Lee S. Those Who Understand: Knowledge Growth in Teaching. Disponível em: https://depts.washington.edu/comgrnd/ccli/papers/shulman_ThoseWhoUnderstandKnowledgeGrowt hTeaching_1986-jy.pdf Acesso em: 15 mar 2020.

SHULMAN, Lee S. Knowledge and teaching: Foundations of the new reform. Disponível em: https://d1wqtxts1xzle7.cloudfront.net/30505333/shulman-with-cover-page-

v2.pdf?Expires $=1630764164 \&$ Signature $=$ MWBiyvgEb4kletemajtIQ6BMqeYfmluI1IScGFxI910t58Dpvbi2rODpkn2t7AWyQQ2mdkLgEgwzSOG0fB6Bi cR2DFOc WJHiMujHfreR3ijqlyeQX8mjebdIHYxrWOWBQIPKebpFQwSEaatiVDIfzxumOmWdXas6WDR7cq8S0sJfSj4ZtQ6I7GgpJ3imh9IQff4C-ZNjV8DlgsqS13|42Wc9vDgx99IxIVujvEBJ2oEzXvjFUjx7 2V8neW4TkmCDX9wltMDS5ITzUOJWEihjVO09vwDLrMFWpw6 cr1XRnGYTDMAv1tNbwKMsSx5LXX0jXO7q4d6cGwpOgmPIQ_\&Key-PairId=APKAJLOHF5GGSLRBV4ZA Acesso em: 15 mar 2020. 